\title{
Chemical Constituents from Himatanthus articulata
}

\author{
Alaide de Sá Barreto ${ }^{\mathrm{a}}$, Mário Geraldo de Carvalho ${ }^{\mathrm{a}}$, Ivanilton de Almeida \\ Nery $^{\mathrm{a}}$, Luiz Gonzaga ${ }^{\mathrm{b}}$ and Maria Auxiliadora Coelho Kaplan ${ }^{\mathrm{b}}$ \\ ${ }^{a}$ Departamento de Química, Instituto de Ciências Exatas, Universidade Federal Rural \\ do Rio de Janeiro, 23851-970 Seropédica - RJ, Brazil \\ ${ }^{\mathrm{b}}$ Núcleo de Pesquisa de Produtos Naturais, Universidade Federal do Rio de Janeiro,
} 21991-590 Rio de Janeiro - RJ, Brazil

Received: April 30, 1998

\begin{abstract}
O estudo fitoquímico de Himatanthus articulata (Vahl) Woodson permitiu o isolamento e identificação de estigmasterol, sitosterol, cicloartenol, $3 \beta$-cinamato de $\alpha$-amirina $+3 \beta$-cinamato de $\beta$-amirina, $3 \beta$-acetato de $\alpha$-amirina, $3 \beta$-acetato de $\beta$-amirina, $3 \beta$-cinamato de lupeol, $3 \beta$-acetato de lupeol, ácido ursólico, metilmioinositol, ácido $1 \beta$-O- $\beta$-D-glucopiranosilplumérico, $1 \beta$-O- $\beta$-D-glucopiranosilplumerídio, plumericina e isoplumericina. Essas substâncias e alguns derivados foram identificados com base na análise dos espectros de IV, EMIE e RMN de ${ }^{1} \mathrm{He}{ }^{13} \mathrm{C}$.

Chemical investigation of Himatanthus articulata (Vahl) Woodson led to the isolation of stigmasterol, sitosterol, cycloartenol, $\alpha$-amyrin-3 $\beta$-O-cinnamoyl, $\beta$-amyrin-3 $\beta$-O-cinnamoyl, lu-

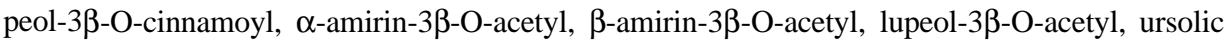
acid, methylmyoinositol, $1 \beta-\mathrm{O}-\beta$-D-glucopyranosylplumeric acid, plumeride-1 $\beta-\mathrm{O}-\beta$-D-glucopyranosyl, plumericin and isoplumericin. Spectroscopic analysis (IR, ${ }^{1} \mathrm{H},{ }^{13} \mathrm{C}-\mathrm{NMR}$ and MS) were used for the identification of these compounds and some derivatives.
\end{abstract}

Keywords: Himatanthus articulata, Apocynaceae, steroids, triterpenes, iridoid glucosides

\section{Introduction}

Himatanthus articulata (Vahl) Woodson, (Apocynaceae) is a tree occurring in the Amazon region. The local population uses its bark and latex as a tonic and as a antisyphilitic ${ }^{1}$. Species belonging to the genus Himatanthus have been scarcely mentioned in the chemical literature. Earlier studies of Himatanthus articulata recorded the isolation of the acetate and cinnamate of $\alpha$-amyrin and of $\beta$-amyrin ${ }^{2-4}$. From $H$. phageadaenica were isolated and identified an acetylated mixture of the triterpenes $\alpha$-amyrin and lupeol, in addition to sitosterol and the iridoid lactones: plumericin, allamandin and isoplumericin, as well as a mixture of plumieride glucoside and sucrose ${ }^{5}$. A glycosylplumieride has been also isolated from $H$. lancifolius ${ }^{6,7}$, formerly known as Plumeria lancifolia ${ }^{8}$.

\section{Results and Discussion}

Latex of Himatanthus articulata collected near Macapá-AP, Brazil, was extracted with hexane and methanol.
The hexane extract yielded, after several chromatograpic steps, a mixture of the cinnamate of $\alpha$-amyrin and $\beta$-amyrin (6 and 7) along with the acetate of lupeol (4), cinnamate of lupeol (5) and cycloartenol (3). Leaves and bark of this plant were extracted successively with hexane and methanol. The methanolic extract of leaves consisted almost exclusively of ursolic acid $(90 \%, \mathbf{8})$. The hexane extract of bark yielded, besides the terpenoids $\mathbf{4}$ and $\mathbf{5}$, stigmasterol (9) and sitosterol (10). The methanolic extract of bark yielded the spirolactone iridoids (1 and 2), plumericin (12), isoplumericin (13) and methylmyoinositol (11). Compounds $1,3,5,8,9,10$ and 11 have been isolated for the first time from the genus Himatanthus.

The fractions obtained by chromatographic fractionation of the acetylated methanolic extract yielded the iridoid derivatives 1a and 2a. The ${ }^{13} \mathrm{C}-\mathrm{NMR}$ (HBBD and DEPT) spectra of 1a showed five signals for $\delta_{\mathrm{CH}}$ and one $\delta_{\mathrm{CH} 2}$ of the sugar unit. Seven $\delta_{\mathrm{H}}$ signals in the ${ }^{1} \mathrm{H}-\mathrm{NMR}$ spectrum have been assigned to the same sugar moiety by the ho- 
monuclear ${ }^{1} \mathrm{H},{ }^{1} \mathrm{H}-\mathrm{COSY}$ and also by comparison with literature data ${ }^{5,9}$. The peaks at $m / z 332(2.0 \%$, 1f) and 331 $(20.0 \%, \mathbf{1 g})$ observed in the EIMS spectra are compatible with the 2,3,4,6-tetra-O-acetyl-1-O- $\beta$-D-glucopyranosyl group. The cross peaks observed in the $2 \mathrm{D}{ }^{1} \mathrm{H},{ }^{13} \mathrm{C}-\mathrm{COSY}-$ ${ }^{1} \mathrm{~J}_{\mathrm{CH}}$ allowed to correlation of the signals at $\delta_{\mathrm{H}} 1.48(\mathrm{~d}$, $6.6 \mathrm{~Hz}), 5.60$ (q, 6,6 Hz), 5.10 (br) in the ${ }^{1} \mathrm{H}-\mathrm{NMR}$ spectrum, respectively, with a methyl group and two hydrogen atoms attached to oxygenated carbons that are connected with carbons at $\delta_{\mathrm{C}} 19.40,66.18$ and $93.33 \mathrm{ppm}$. The same spectrum showed four proton signals at 5.38 (br, $6.8 \mathrm{~Hz}$ ), $6.96(\mathrm{br}), 6.43(\mathrm{~m})$ and $7.41(\mathrm{br})$ connected to the $\mathrm{sp}^{2}$ carbons at $\delta_{\mathrm{C}} 144,50,128,66,148,50$ and $151,75 \mathrm{ppm}$. Comparison of these data and the remaining ${ }^{1} \mathrm{H}$ and ${ }^{13} \mathrm{C}$ chemical shift of the acetyl derivative 1a (see Experimental) with those reported for plumeride $e^{5,10}$ allowed to identification of the aglycone of $\mathbf{1}$. Peaks in the EIMS spectrum corresponding to fragments $\mathbf{1 b - 1 e}$ are in agreement with the structure of 1 . To establish the $\beta$-D-glucopyranosyl moiety at the $\beta$-position of the carbon $\mathrm{C}-1$, the $\delta_{\mathrm{C}-1}(93,33$ ppm) and $\delta_{\mathrm{H}-1}(5,10$; br) were compared with the models $1 \beta$-O-acetyl $(\mathbf{2 b})^{9}$ and 1 $\beta$-O-glucopyranosyl $(\mathbf{2 c})^{9}$, and with those of the penta-O-acetylplumeride glucoside (2a), previously isolated from $H$. phageadaenica. ${ }^{5}$ The presence of a carboxylic acid group in $\mathbf{1}$ was confirmed by the signals at $\delta \mathrm{H} 3.93(\mathrm{~s}), \delta \mathrm{C} 51.50\left(\mathrm{CH}_{3}\right)$ and $170.50(\mathrm{C})$ in the ${ }^{1} \mathrm{H}$ - and ${ }^{13} \mathrm{C}$-NMR spectra of the methyl ester obtained after treatment of la with diazomethane.

The structures of plumeride glucoside (2), plumericin (12) and isoplumericin (13) were determined by analysis of ${ }^{1} \mathrm{H}$ - and ${ }^{13} \mathrm{C}-\mathrm{NMR}$ spectra and comparison with literature data ${ }^{5,11}$. These iridoids have been commonly reported in the Plumeria genus ${ }^{10,11}$.

Identification of compounds 3-10 was achieved by analysis of IR, NMR and EIMS spectra and comparison with literature data. The ${ }^{1} \mathrm{H}-\mathrm{NMR}$ spectra allowed the identification of the respective series of 3 (cycloartene), 4-8 (pentacyclic triterpenes) and 9-10 (steroids). Analysis of ${ }^{13} \mathrm{C}-\mathrm{NMR}$ data and the use of the Olea et al ${ }^{12}$ methodology led to the confirmation of the triterpene series as cycloartene $(3)^{13}$, lupene $(4,5)$, ursene $(6,8)$ and oleanene (7). ${ }^{14-16}$ The main peaks observed in the mass spectra are compatible with those fragment ions expected for triterpene units.

The acetate unit in $\mathbf{4}$ was identified by the $\delta_{\mathrm{C}=\mathrm{O}}(\mathbf{1 7 1 . 3 0}$ ppm) and $\delta_{\mathrm{CH} 3}(21.30 \mathrm{ppm})$ in the ${ }^{13} \mathrm{C}-\mathrm{NMR}$ spectrum as well as the $\delta_{\mathrm{H}}(2.05 \mathrm{ppm})$ in the ${ }^{1} \mathrm{H}-\mathrm{NMR}$ spectrum.

The trans cinnamate units of 5-7 were identified by analysis of IR data, showing signals at $1725 \mathrm{~cm}^{-1}\left(\mathrm{v}_{\mathrm{C}=\mathrm{O}}\right.$, conjugated ester), 1600, $1500 \mathrm{~cm}^{-1}\left(\mathrm{v}_{\mathrm{C}=\mathrm{C}}\right.$, aromatic) and $v_{\mathrm{C}-\mathrm{O}}$ at $1250 \mathrm{~cm}^{-1}$. The ${ }^{1} \mathrm{H}-\mathrm{NMR}$ spectrum showed two doublets at $\delta_{\mathrm{H}} 7.60-7.68(16.0 \mathrm{~Hz}, \mathrm{H}-\alpha)$ and 6.45-6.48 (16.0
$\mathrm{Hz}, \mathrm{H}-\beta)$ and two signals for five aromatic protons [7.59 (m; H-2',6') and 7.37 (m; H-3',4',5')]. ${ }^{13} \mathrm{C}-\mathrm{NMR}$ spectrum showed $\delta_{\mathrm{C}} 166,20-166,80(\mathrm{C}=\mathrm{O}), 134,50-134,70\left(\mathrm{C}-1{ }^{\prime}\right)$,

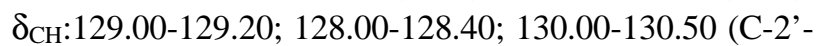
6') and $118.30-118.70 \mathrm{ppm}(\mathrm{C}-\alpha)$ which are similar to those found in the literature ${ }^{16}$.

The chemical shifts of $\mathrm{H}-3\left[\delta_{\mathrm{H}} 4.45(\mathrm{dd}, \mathrm{J}=10,0\right.$ and 4,0 Hz)] in 4 and 5 and [ $\delta_{\mathrm{H}} 4.72(\mathrm{dd}, 11,0$ and 7,0 Hz)] in 6 and 7 as well as the carbon chemical shifts of C-3 $\left[\delta_{\mathrm{C}}\right.$ $80.90\left(\mathbf{4}, \mathbf{5}, 6\right.$ and 7)], C-2 [ $\delta_{\mathrm{C}} 23.70$ (4 and 5), $23.50(\mathbf{6})$, $23.70(7)]$ and $\mathrm{C}-4\left[\delta_{\mathrm{C}} 37.70(\mathbf{4}, \mathbf{5}), 37.60(\mathbf{6}, \mathbf{7})\right]$ were compared with those of $3 \beta-\mathrm{O}$-acetyl and $3 \beta-\mathrm{O}$-cinnamoyl triterpene derivatives in the literature ${ }^{15,16}$ to establish the $\beta$-position of $\mathrm{O}$-acetyl and $\mathrm{O}$-cinnamoyl moieties at C-3. A literature search revealed the absence of NMR spectral data for $\mathbf{1 a}$ and ${ }^{13} \mathrm{C}$-NMR data for $\mathbf{5}$ and $\mathbf{6}^{14,17}$. Therefore, these assignments are described in the experimental part.

The structure of compound $\mathbf{8}$ was established as following: the IR signals at $3450 \mathrm{~cm}^{-1}\left(\mathrm{~V}_{\mathrm{O}-\mathrm{H}}\right), 1620 \mathrm{~cm}^{-1}\left(\mathrm{~V}_{\mathrm{C}=\mathrm{C}}\right)$ and $1080 \mathrm{~cm}^{-1}$ ( $\mathrm{v}_{\mathrm{C}-\mathrm{O}}$, secondary alcohol), the ${ }^{1} \mathrm{H}-\mathrm{NMR}$ spectrum showed signals at $\delta_{\mathrm{H}} 5,25$ (m, H-12), 3,15 (m, $\mathrm{H}-3$ ), 2,2 (d, 14.0 Hz, H-18) and signals relative to seven methyl groups at $\delta_{\mathrm{H}} 0.75,0.84,0.96,0.96,1,11(\mathrm{~s}) ; 0.89$ and $0.95(\mathrm{~d}, 6.0 \mathrm{~Hz})$. These data are in agreement with a pentacyclic acid triterpene of the ursane seires. The peaks at $m / z 456\left(\mathrm{M}^{+}, 11 \%\right), 207$ (47\%), 208 (11\%), 248 (100\%), $189(17 \%)$ observed in the mass spectrum, along with analysis of 1D and 2D NMR spectra of the acetyl derivative $\mathbf{8 a}$ and comparison with those of the literature ${ }^{18-20}$, allowed identification of the structure of the known triterpene 8 . The derivatives $\mathbf{8 b}$ and $\mathbf{8 c}$ showed $\delta_{\mathrm{C}}$ : 171.0, $21.08\left(\mathrm{H}_{3} \mathrm{CCO}\right)$, $51.41\left(\mathrm{H}_{3} \mathrm{C}-\mathrm{O}\right)$ in the ${ }^{13} \mathrm{C}-\mathrm{NMR}$ spectrum and $\delta_{\mathrm{H}} 2,04(\mathrm{~s}$, $\mathrm{H}_{3} \mathrm{CCO}$ ), 3,60 (s, $\mathrm{H}_{3} \mathrm{C}-\mathrm{O}$ ) in the ${ }^{1} \mathrm{H}-\mathrm{NMR}$ spectrum which were used to confirm the structure of $\mathbf{8}$ as urs-3 $\beta$-hydroxy12-en-28-oic acid (ursolic acid).

The mixture of sterols $\mathbf{9}$ and $\mathbf{1 0}$ was identified by the signals at $\delta_{\mathrm{H}} 0.62(\mathrm{~s}), 1.05(\mathrm{~s}), 0.74-0.98(\mathrm{~m})$ in the ${ }^{1} \mathrm{H}-\mathrm{NMR}$ spectrum corresponding to the absorptions of the methyl groups, the $\delta_{\mathrm{H}} 3.49(\mathrm{H}-3)$, besides the signals at $\delta_{\mathrm{H}} 5.10(\mathrm{~m}$, $\mathrm{H}-22$ and $\mathrm{H}-23,9), \delta_{\mathrm{H}} 5.50$ (d br, H-6, 9 and 10) of the olefinic protons. These data along with the ${ }^{13} \mathrm{C}-\mathrm{NMR}$ and EIMS spectral analysis of that mixture, and comparison with literature data ${ }^{21}$, led us to identify $\mathbf{9}$ as stigmasterol and $\mathbf{1 0}$ as sitosterol.

The structure of the carbohydrate was established as methylmioinositol (11) by comparative analysis of chemical shifts of the monoprotoned carbon atoms observed in the ${ }^{13} \mathrm{C}-\mathrm{NMR}$ (HBBD and DEPT) spectra with values described in the literature ${ }^{22}$. The spectral analysis of the derivative 11a including ${ }^{1} \mathrm{H}-\mathrm{NMR}, 1 \mathrm{D}$ and $2 \mathrm{D}\left({ }^{1} \mathrm{H},{ }^{1} \mathrm{H}-\right.$ COSY) and ${ }^{1} \mathrm{H},{ }^{13} \mathrm{C}-\mathrm{COSY},{ }^{\mathrm{n}} \mathrm{J}_{\mathrm{CH}}, \mathrm{n}=1,2$ and 3) confirmed structure $11^{23}$. 

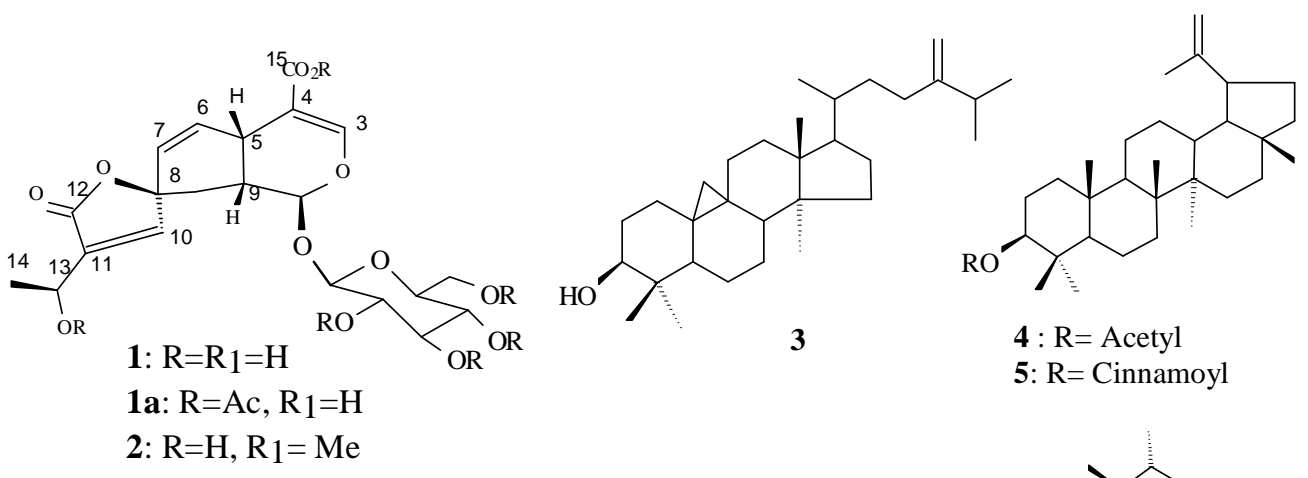

3

4: $\mathrm{R}=$ Acetyl

5: $\mathrm{R}=$ Cinnamoyl

2a: $\mathrm{R}=\mathrm{Ac}, \mathrm{R}_{1}=\mathrm{Me}$<smiles>CC(C)(C)C(=O)/C=C/c1ccccc1</smiles>

Cinnamoyl

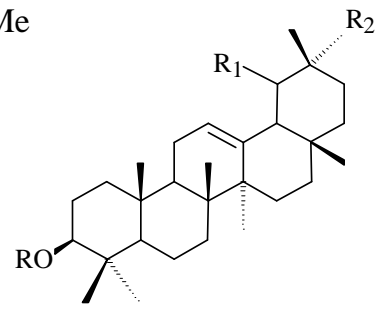

6: $\mathrm{R} 1=\mathrm{CH}_{3}, \mathrm{R}_{2}: \mathrm{H}, \mathrm{R}=$ Cinnamoyl

7: $\mathrm{R} 1=\mathrm{H}, \mathrm{R}_{2}=\mathrm{CH}_{3}, \mathrm{R}=$ Cinnamoyl

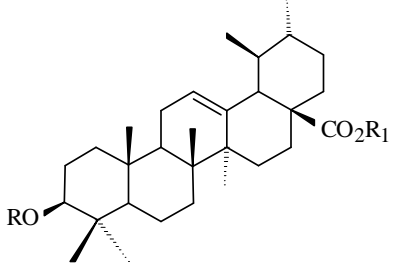

$8: \mathrm{R}=\mathrm{H}, \mathrm{R}_{1}=\mathrm{H}$

8a: $\mathrm{R}=\mathrm{Ac}, \mathrm{R}_{1}=\mathrm{H}$

8b: $\mathrm{R}=\mathrm{Ac}, \mathrm{R}_{1}=\mathrm{Me}$

8c: $R=H, R_{1}=M e$<smiles>CCC(/C=C/C(C)C1CCC2C3CC=C4CC(O)CCC4(C)C3CCC12C)C(C)C(C)C</smiles>

9: $\Delta 22,23$

10: 22,23-dihydro

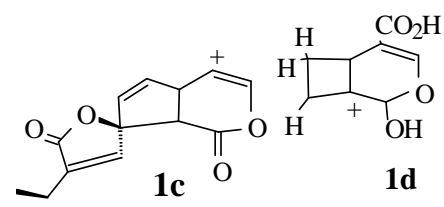

$m / z: 229(3.0 \%)$

$m / z: 169(22.0 \%)$<smiles>[O-]C1=COC=CC1</smiles>

1e $m / z: 109(24)$

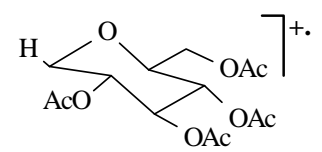

1f

$m / z: 332(2.0 \%)$

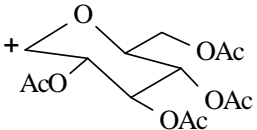

19

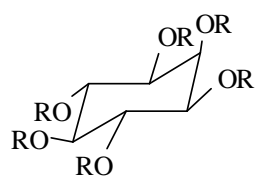

11: $\mathrm{R}=\mathrm{H}$

11a: $\mathrm{R}=\mathrm{Ac}$

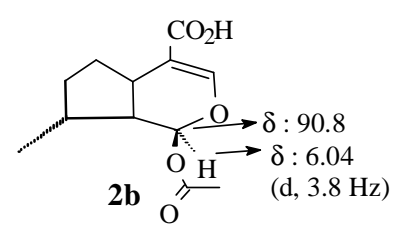

$\mathrm{O}^{2 / 1}$

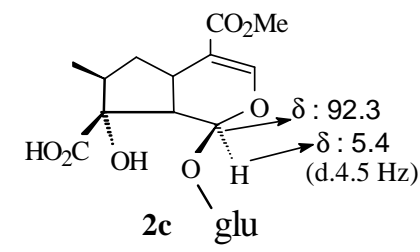<smiles>[R]C(=[R])[C@@H]1C=C[C@@H]2O[C@@H]3C(=C([R])[R])C(=O)O[C@]34C=C[C@@H]1[C@@H]24</smiles>

12: $\mathrm{R}=\mathrm{H}, \mathrm{R}_{1}=\mathrm{Me}$

13: $\mathrm{R}=\mathrm{Me}, \mathrm{R}_{1}=\mathrm{H}$

\section{Experimental}

General procedure

Melting points were determined using a Kofler hot stage instrument and are uncorrected. The NMR spectra were recorded in the Fourier transform mode on a Bruker AC-200 ( $\left.{ }^{1} \mathrm{H}: 200 \mathrm{MHz},{ }^{13} \mathrm{C}: 50.3 \mathrm{MHz}\right)$ spectrometer. The solvents used were $\mathrm{CDCl}_{3}$ and Methanol- $\mathrm{d}_{6}$ with TMS as the internal standard. Mass spectra were obtained with GC-MS HP5988A at the Instituto de Química of the Uni- 
versidade de São Paulo and with the Micro Mass-12 of the NPPN-Laboratório de Tecnologia Farmacêutica-Universidade Federal da Paraiba. Infrared spectra were recorded as $\mathrm{KBr}$ discs on a Perkin Elmer 1420 spectrophotometer. Column chromatography was run using silica gel S (Riedel $0.032-0.063 \mathrm{~nm}$ ) for separation by gravity and with Merck 230/400 Mesh 60A for flash column chromatography. TLC analysis was done with silica gel G (Merck or Aldrich) and the spots were visualized by UV $(254 \mathrm{~nm})$ irradiation, reaction with an alcoholic solution of phosphomolybdic acid followed by heat, or by exposure to iodine vapor. Liquid-liquid partition chromatography was performed using the CCC Ito apparatus with a coil \#10 (2.60 mm, $400 \mathrm{~mL}$ vol. approx., PTFE tubing). The preparative centrifugal chromatography was run with a Chromatotron from Harrison Research.

\section{Plant material}

Bark, leaves and latex of $H$. articulata (Vahl) Woodson were collected by botanist Benedito Vitor Rabello in Amapá state, Brazil. Authentication was performed by comparing it with a voucher specimen (№ 0522) preserved at the Herbário Amapaense (HAMAB) of the IEPA, Macapá - AP, Brazil.

\section{Extraction and isolation}

The pulverized air-dried bark material $(1.7 \mathrm{~kg})$ and leaves $(1.4 \mathrm{~kg})$ were extracted by maceration at room temperature successively with hexane and methanol. The solvents were removed under vacuum to yield $10.8 \mathrm{~g}$ of hexanic extract and $30.0 \mathrm{~g}$ of methanolic extract from the bark and $73.6 \mathrm{~g}$ of hexanic extract and $50.0 \mathrm{~g}$ of methanolic extract from the leaves. The latex dissolved in $\mathrm{CHCl}_{3}$ was filtered under vacuum and removal of the solvent gave $21.5 \mathrm{~g}$ of extract. The residue $(5.0 \mathrm{~g})$ of the latex was chromatographed on a nylon dried column of silica gel and eluted with $\mathrm{CH}_{2} \mathrm{Cl}_{2}$ and 15 fractions were collected. These fractions were analysed by TLC and submitted to centrifugal preparative chromatography (Chromatotron) with hexane/dichloromethane as eluents. From the fractions 1-4 was isolated the mixture of 6 and 7 (m.p.: 85-90, $70.0 \mathrm{mg}$ ); fractions 5-15 were fractioned by flash chromatography on a silica gel column to yield 3 (m.p.: $167-169^{\circ}, 170.0 \mathrm{mg}$ ), 9 and 10 (m.p.: 130-132, $172.0 \mathrm{mg}$ ). and a mixture of these compounds along with aliphatic acids. The hexanic extract from bark $(5.0 \mathrm{~g})$ was fractioned on silica gel column using $\mathrm{CH}_{2} \mathrm{Cl}_{2} /$ ethyl acetate as eluents in increasing polarities and 80 fractions were collected. Removal of the solvent give 5 (amorphous material, $60.0 \mathrm{mg}$ ) and $\mathbf{4}$ and $\mathbf{5}(100.0 \mathrm{mg}$ ) along with a mixture of these compounds and a mixture of aliphatic acids. The methanolic extract (30.0 g) from bark was submitted to acid-base extraction. The solution was concentrated and lyophylised to yield the HABM fraction which was dried in an Abderhalden apparatus. IR analysis of the fraction confirmed the absence of an ester carbonyl. The HABM was acetylated with acetic anhydride and pyridine to obtain HABM-Ac. Part of this product (4.0 g) was fractionated in a column of silica gel using chloroform as eluent yielding 17 fractions. Hexane was added to the these fractions yielding a solid 11a (MP: $215-217^{\circ}, 45 \mathrm{mg}$ ) and a solution with a mixture of iridoids, carbohydrates and other compounds. This mixture was partitionated by $\mathrm{CCC}$ (Ito) with $\mathrm{CHCl}_{3}: \mathrm{MeOH}: \mathrm{H}_{2} \mathrm{O}(35: 40: 25)$ using $\mathrm{CHCl}_{3}$ as the mobile phase. Aliphatic acids were found in the mobile phase. The remaining phase was fractionated by preparative centrifugal chromatography (Chromatotron) using hexane/ethyl acetate/methanol in increasing polarities to yield 11a (370 mg), 1a (amorphous material, $40 \mathrm{mg}$ ) and 2a (amorphous material, $15 \mathrm{mg}$ ). NMR spectrum and TLC analysis of the hexanic extract from leaves revealed the presence of the same compounds found in the hexanic extract from bark. The portion of methanolic extract that was soluble in methanol gave 8 (m.p.: 226-228, $25.0 \mathrm{~g}$ ) after addition of ethyl acetate.

\section{Acetylation of the fraction $H A B M$ and $\mathbf{8}$}

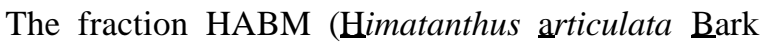
Methanol) and $\mathbf{8}$ were, separately, dissolved in a mixture of pyridine and $\mathrm{Ac}_{2} \mathrm{O}(1: 1)$ and the solution was allowed to stand for $24 \mathrm{~h}$ at room temperature. The usual work up yielded HABM-Ac (amorphous solid, $4.0 \mathrm{~g}$ ) and 8a (m.p.: $\left.221-223^{\circ}, 1.8 \mathrm{~g}\right)$.

\section{Methylation of $\mathbf{8}, \mathbf{8 a}$ and $\mathbf{1 a}$}

The ethereal solution of diazomethane previously prepared from Diazald was added in excess to solutions of $\mathbf{8}$, 8a and 1a in methanol to yield 8c (m.p.: $189-91{ }^{\circ} \mathrm{C}, 60.0$ mg), 8b (m.p.: 111-113 ${ }^{\circ} \mathrm{C}, 1.8$ g) and 2a (m.p.: 119$121^{\circ} \mathrm{C}, 15.0 \mathrm{mg}$ ), respectively. The presence of these products was revealed by spectral analysis and comparison with the data of the corresponding natural compounds.

Penta-O-acetylplumeride glucoside acid (1a)

Gum, IR $v_{\text {max }}^{\text {film }}\left(\mathrm{cm}^{-1}\right): 1740,1660,1620,1370,1270$ 1150; ${ }^{1} \mathrm{H}-\mathrm{NMR}\left(\mathrm{MeOD}_{4}, \mathrm{TMS}, \delta\right): 7.41$ (sb, H-10), 6.96 (br s, H-3); 6.43 (dd, $5.8 \mathrm{~Hz} ; 1.5 \mathrm{~Hz}$; H-6), 5.60 (qd, $6.6 \mathrm{~Hz}$; $1.3 \mathrm{~Hz}$; H-13), 5.38 (br d, $5.7 \mathrm{~Hz}$; H-7), 5.16 (t, $8.0 \mathrm{~Hz}$; H-3'), 5.10 (br s, H-1), 5.03 (t, 8.0 Hz; H-4'); 4.96 (t, 8.0 Hz; H-2'), 4.82 (d, 8.0 Hz; H-1'), 4.30 (dd; 12.6 Hz; 4.4 Hz; H-6'a), 4.10 (dd, 12.6 Hz; 2.0 Hz; H-6'b), 3.74 (m, H-5,5'), 3.50 (br d, 6.8 Hz; H-3'), 2.12, 2.06, 2.04, 1.98, 1.96 (s, $\left.\underline{\mathrm{H}}_{3} \mathrm{C}-\mathrm{CO}\right), 1.48$ (d, $\left.6.6 \mathrm{~Hz}, \mathrm{H}-14\right) .{ }^{13} \mathrm{C}-\mathrm{NMR}$ (HBBD, DEPT: $\theta=90$ and $\theta=135)\left(\mathrm{MeOD}_{4}, \delta\right): 174.50$ (C-15), 172.40-171.30 (O-C=O); $171.34(\mathrm{C}-12), 151.75$ (C-10), 148.50 (C-3), 144.50 (C-7), 134.51 (C-11), 128.66 (C-6), 116.50 (C-4), 98.18 (C-1'), 97.33 (C-8), 93.33 (C-1), 73.81 (C-3'), 73.17 (C-5'), 72,16 (C-2'), 69.61 (C-4'), 66.18 (C-13), 62.86 (C-6'), 50.88 (C-9), 40.90 (C-5), 19.40 
(C-14), 21.70 x 5 (H ${ }_{3} \underline{\mathrm{CCO}}$ ); EIMS, $m / z$ (rel. int.): 332 (2, 1f), 331 (20, 1g), 289 (2), 273 (33, 1b), 259 (3), 229 (3, 1c), 169 (22, 1d), 109 (24, 1e), 80 (10), 43 (100).

Lupeoyl 3 $\beta$-O-cinnamate (5): amorphous material

${ }^{13} \mathrm{C}-\mathrm{NMR}$ (HBBD and DEPT: $\theta=90$ and $\theta=135$ ) ( $\left.\mathrm{CDCl}_{3}, \mathrm{TMS}, \delta\right): 166.00$ (C-9'), 151.91 (C-20), 144.51 (C-7'), 134.50 (C-1'), 130.50 (C-4'), 129.05 (C-3',5'), 128.05 (C-2',6'), 118.77 (C-8'), 109.26 (C-29), 80.87 (C3), 55.35 (C-5), 50.32 (C-9), 48.21 (C-18), 48.01 (C-19), 42.87 (C-17), 42.81 (C-14), 40.80 (C-8), 39.90 (C-22), 38.80 (C-13), 38.37 (C-1), 37.70 (C-4), 37.07 (C-10), 35.55 (C-16), 34.18 (C-7), 29.82 (C-21), 27.94 (C-23 and C-15), 25.09 (C-12), 23.69 (C-2), 20.87 (C-11), 19.17 (C-30), 18.20 (C-6), 17.98 (C-28), 16.48 (C-25), 16.18 (C-26), 15.89 (C-24), 14.51 (C-27).

Urs-3 $\beta$-O-cinnamoyl-12-en ( $\beta$-amyrin cinnamate)

${ }^{13} \mathrm{C}-\mathrm{NMR}$ (PND, DEPT: $\theta=90$ and $\left.\theta=135\right)\left(\mathrm{CDCl}_{3}\right.$, TMS, $\delta$ ): 166.75 (C-9'), 144.22 (C-7'), 139.47 (C-13), 134.49 (C1'), 130.07 (C-4'), 128.78 (C-3',5'), 127.99 (C2',6'), 124.27 (C-12), 118.77 (C-8), 80.94 (C-3), 58.88 (C-18), 55.22 (C-5), 47.49 (C-9), 41.59 (C-14), 41.49 (C22), 39.97 (C-8), 39.76 (C-20), 39.55 (C-19), 38.43 (C-1), 37.91 (C-4), 36.76 (C-10), 33.69 (C-17), 32.54 (C-7), 31.20 (C-21), 28.34 (C-15), 28.06 (C-23 and C-28), 26.55 (C-2 and C-16), 23.50 (C-11), 23.34 (C-27), 23.21 (C-29), 21.30 (C-30), 18.61 (C-6), 16.85 (C-26), 15.72 (C-24 and C-25.

\section{Acknowledgments}

The authors are grateful to $\mathrm{CNPq}$ for research fellowships to I.A.N., A. de S.B., M.A.C.K. and to M.G. de C.; for grants from Conselho Nacional de Desenvolvimento Científico e Tecnológico (CNPq), Fundação de Amparo ‘a Pesquisa do Estado do Rio de Janeiro (FAPERJ), Financiadora de Estudos e Projetos (FINEP-PADCT) and to LTF-UFPB and IQ-USP for acquisiton of the mass spectra.

\section{References}

1. Van den Berg, M.E. Plantas Medicinais na Amazônia, Contribuição ao seu conhecimento sistemático; CNPq/PRU/MPEG, Belém, Brasil, 1982.

2. Ferrigni, V.; Nelson, R.; Hasegawa, M. Rev. Latinoamer. Quim. 1976, 7, 146.

3. Kaplan, M.A.C. Tese de Mestado, UFRRJ-Itaguaí Rio de Janeiro, Brazil, 1967.
4. Plummel, M.M. Comp. Rend .Scean. Soc. Biogeogr. 1990, 66, 103.

5. Vanderley, M. de F.; Silva, M.S. da; Gottlieb, H.E.; Braz-Filho, R. J. Braz. Chem. Soc. 1991, 2, 51.

6. Helpern, O.; Schmid, H. Helv. Chim. Acta 1958, 58, 1109.

7. Schmid, H.; Dicshel, H.; Meijer, T.M. Helv.Chim. Acta 1952, 35, 26.

8. Abisch, E.; Teichsteris, T. Helv. Chim. Acta 1960, 53, 1845.

9. Boros, L.A.; Stermitz, F.R. J. of Nat. Prod. 1990, 53, 1055.

10. Adam ,G.; Khoi, N.H.; Bergner, C. ; Lien, N.T. Phytochemistry 1979, 18, 1399.

11. Coppen, J.J.W.; Cobb, A.L. Phytochemistry 1983, 22, 125.

12. Olea, R.S.C.; Roque, N.F. Química Nova 1990, 13, 171.

13. Tereza, J. de P.; Urones, J.G.; Marcos, I.S.; Basane, P.; Sexmero, M.J.C.; Moro, R.F. Phytochemistry 1987, 26, 1767.

14. Mahato, S.B.; Kundu, A.P. Phytochemistry 1994, 37, 1517.

15. Sobrinho, D.C.; Hauptly, M.B.; Appolinario, E.V.; Kollenz, C.L.M.; Carvalho, M.G. de; Braz-Filho, R. J. Braz. Chem. Soc. 1991, 2, 15.

16. Bhattacharyya, J.; Barros, C.B. Phytochemistry 1986, 25, 274.

17. Bucknigman, V. Dictionary of Natural Products, Chapman \& Hall, 2-65, London, 1994.

18. Seo, S.; Tomita, Y.; Tori, K. Tetrahedron Letters 1975, 7 .

19. Nozaki, H.; Suzuki, H.; Hirayama, T.; Kasai, R.; Wu, R.Y.; Lee, K.H. Phytochemistry 1986, 25, 479.

20. Matsunaga, S.; Tanaka, R.; Akagi, M. Phytochemistry 1988, $27,535$.

21. Goulart, M.O.F.; Sant'Ana, A.E.G.; Lima, R.A. de; Cavalcante, S.H.; Carvalho, M.G. de; Braz-Filho, R. Química Nova 1993, 16, 95.

22. Braitmaier, E.; Voelter, W. Carbon-13 NMR Spectroscopy, High-Resolution Methods and Applications in Organic Chemistry and Biochemistry ( $3^{\text {rd }}$ ed.) VCH, Weinheim, 1987.

23. Dutra, N.N., Alves, H. de M.; Carvalho, M.G. de; Braz-Filho, R. Química Nova 1992, 15, 10. 